\title{
Synergistic induction of local glucocorticoid generation by inflammatory cytokines and glucocorticoids: implications for inflammation associated bone loss
}

\author{
K Kaur, ${ }^{1}$ R Hardy, ${ }^{1}$ M M Ahasan, ${ }^{1}$ M Eijken, ${ }^{2}$ J P van Leeuwen, ${ }^{2}$ A Filer, ${ }^{3}$ A M Thomas, ${ }^{4}$ \\ K Raza, ${ }^{3}$ C D Buckley, ${ }^{3}$ P M Stewart, ${ }^{1}$ E H Rabbitt, ${ }^{1}$ M Hewison, ${ }^{5}$ M S Cooper ${ }^{1}$
}

${ }^{1}$ School of Clinical and

Experimental Medicine, Institute

of Biomedical Research,

University of Birmingham,

Birmingham, UK

${ }^{2}$ Department Internal Medicine,

Erasmus Medical Center,

Rotterdam, The Netherlands

${ }^{3}$ School of Immunity and

Infection, Institute of Biomedical

Research, University of

Birmingham, Birmingham, UK

${ }^{4}$ Royal Orthopaedic Hospital

NHS Foundation Trust,

Birmingham, UK

${ }^{5}$ Department of Orthopedic

Surgery, UCLA-Orthopedic

Hospital, Los Angeles,

California, USA

\section{Correspondence to}

Dr Mark S Cooper,

Endocrinology, School of Clinical and Experimental Medicine,

University of Birmingham,

Queen Elizabeth Hospital,

Edgbaston, Birmingham B15

2TH, UK;

M.S.Cooper@bham.ac.uk

$\mathrm{KK}$ and $\mathrm{RH}$ contributed equally.

Accepted 9 June 2009

Published Online First

22 June 2009

\begin{abstract}
Objectives Synovial fibroblasts and osteoblasts generate active glucocorticoids by means of the $11 \beta$-hydroxysteroid dehydrogenase type $1(11 \beta$ HSD1) enzyme. This activity increases in response to proinflammatory cytokines or glucocorticoids. During inflammatory arthritis synovium and bone are exposed to both these factors. This study hypothesised that glucocorticoids magnify the effects of inflammatory cytokines on local glucocorticoid production in both synovium and bone.
\end{abstract}

Methods The effects of inflammatory cytokines (IL-1ß/ tumour necrosis factor alpha; TNF $\alpha$ ) and glucocorticoids, alone or combined, were assessed on the expression and activity of $11 \beta$-HSD1 in primary synovial fibroblasts, primary human osteoblasts and MG-63 osteosarcoma cells. A range of other target genes and cell types were used to examine the specificity of effects. Functional consequences were assessed using IL-6 ELISA.

Results In synovial fibroblasts and osteoblasts, treatment with cytokines or glucocorticoids in isolation induced $11 \beta-H S D 1$ expression and activity. However, in combination, $11 \beta$-HSD1 expression, activity and functional consequences were induced synergistically to a level not seen with isolated treatments. This effect was seen in normal skin fibroblasts but not foreskin fibroblasts or adipocytes and was only seen for the $11 \beta$-HSD1 gene. Synergistic induction had functional consequences on IL-6 production.

Conclusions Combined treatment with inflammatory cytokines and glucocorticoids synergistically induces $11 \beta$ HSD1 expression and activity in synovial fibroblasts and osteoblasts, providing a mechanism by which synovium and bone can interact to enhance anti-inflammatory responses by increasing localised glucocorticoid levels. However, the synergistic induction of $11 \beta$-HSD1 might also cause detrimental glucocorticoid accumulation in bone or surrounding tissues.

Inflammatory joint disease is associated with focal bone loss, periarticular osteopenia and generalised osteoporosis. Bone loss is associated with uncoupling of bone resorption from formation but the basis for this is poorly understood. ${ }^{1}{ }^{2}$ Systemic bone loss in other inflammatory diseases is exaggerated by treatment with therapeutic glucocorticoids. ${ }^{3}$ How inflammation sensitises bone to glucocorticoids is unknown. We have previously shown that synovial fibroblasts and osteoblasts generate active glucocorticoids through the expression of $11 \beta$-hydroxysteroid dehydrogenase type 1 (11 $\beta$-HSD1). ${ }^{4-7}$ This enzyme converts inactive glucocorticoids (cortisone and prednisone) to their active counterparts (cortisol and prednisolone). This activity increases in vitro in response to proinflammatory cytokines or glucocorticoids. ${ }^{4} 58$ Glucocorticoid generating capacity in synovial tissue correlates with the erythrocyte sedimentation rate in patients with inflammatory arthritis. ${ }^{6}$ Systemic measures of $11 \beta$-HSD1 activity also predict the effect of therapeutic glucocorticoids on bone markers in healthy men. ${ }^{9}$ However, in clinical situations both proinflammatory cytokines and glucocorticoids are likely to impact on $11 \beta$-HSD1 expression but the effect of these factors in combination is unclear. Typically, glucocorticoids inhibit proinflammatory cytokine signalling ${ }^{10}$ but the presence of high $11 \beta$-HSD1 activity in inflamed joints despite high glucocorticoid levels suggested that glucocorticoids fail to suppress the effect of proinflammatory cytokines on $11 \beta-H S D 1$. We examined this hypothesis in primary synovial fibroblasts and osteoblasts. We found that $11 \beta-H S D 1$ expression and activity increased dramatically in response to the combination of inflammatory cytokines and glucocorticoids. This induction was specific for $11 \beta-H S D 1$, did not occur in foreskin fibroblasts or adipocytes, and had functionally important effects.

\section{METHODS \\ Cell culture}

Reagents were obtained from Sigma (Poole, UK) unless stated. Primary synovial fibroblasts were generated from synovial tissue obtained from patients with rheumatoid arthritis (by 1987 American Rheumatism Association classification criteria) during knee arthroplasty as described. ${ }^{4}$ Isolated fibroblasts were grown in RPMI-1640 medium containing $1 \%(\mathrm{v} / \mathrm{v})$ non-essential amino acids (NEAA), $1 \%$ penicillin/streptomycin, $1 \%$ sodium pyruvate, $2 \mathrm{mM}$ glutamine and $20 \%$ fetal bovine serum (FBS; Labtech, Sussex, UK). Hs-68 cells, a primary culture of human foreskin fibroblasts, were cultured in Dulbecco's modified Eagle's medium (DMEM) with 20\% FBS and $2 \mathrm{mM}$ glutamine.

Primary human osteoblasts were cultured from bone chips obtained at orthopaedic surgery as 
described. ${ }^{8}$ Trabecular bone was treated with $2 \%$ type 1 collagenase for $2 \mathrm{~h}$, washed then cultured in DMEM/F12 containing $10 \% \mathrm{FBS}, 1 \% \mathrm{NEAA}$ and $2 \mathrm{mmol} /$ litre glutamine. MG-63 cells were cultured in minimal essential medium with $10 \%$ FBS, $1 \%$ NEAA and $2 \mathrm{mmol} /$ litre glutamine. SV-HFO cells were cultured in $\alpha$ minimal essential medium (Gibco, Paisley, UK) with $20 \mathrm{mmol} /$ litre HEPES, pH 7.5, streptomycin/penicillin, $1.8 \mathrm{mmol} / 1$ calcium chloride, $2 \% \mathrm{FBS}$ and $10 \mathrm{mmol} /$ litre $\beta$-glycerophosphate.

Chub-S7 cells, a human pre-adipocyte cell line, were cultured in DMEM/F12 with $10 \%$ FBS to maintain a preadipocyte phenotype. Treatment with DMEM/F12 with $10 \%$ FBS, $17 \mu \mathrm{M}$ D-panthotenic acid, $33 \mu \mathrm{M}$ biotin, $1 \mathrm{nM}$ triiodothyronine, $166 \mathrm{nM}$ insulin, $1 \mu \mathrm{M}$ cortisol and $1 \mu \mathrm{M}$ GW1929 was used to generate mature adipocytes. Patients gave informed consent and the study had Local Research Ethics Committee approval.

Cells were cultured with proinflammatory cytokines (IL-1 $\beta$ / tumour necrosis factor alpha (TNF $\alpha) ; 0.1-10 \mathrm{ng} / \mathrm{ml})$ and glucocorticoids (cortisol/dexamethasone; 1-100 nM) alone or in combination.

\section{RNA extraction and real-time PCR}

RNA was extracted using TRI reagent (Sigma). Aliquots ( $1 \mu \mathrm{g})$ were reverse transcribed using random hexamers (Promega, Madison, Wisconsin, USA). 5 The expression of messenger RNA for $11 \beta$-HSD1, $11 \beta$-HSD2, GR $\alpha$, GR $\beta$, osteoprotegerin and cyclooxygenase- 2 was assessed using real-time PCR using an ABI7500 system (Applied Biosystems, Warrington, UK) with $18 \mathrm{~S}$ as internal reference. Reactions contained TaqMan PCR mastermix, 500-900 nmol primers, 100-200 nmol TaqMan probe and 25-50 ng complementary DNA. Data were obtained as $\mathrm{Ct}$ values and used to determine $\Delta \mathrm{C}$ t values (Ct target $-\mathrm{Ct}$ $18 \mathrm{~S})$. Fold-change in expression was determined by subtracting $\Delta$ Ct values for treated cells from their control. The resulting $\Delta \Delta \mathrm{C}$ t values were used to calculate fold-change using the equation $2^{\Delta \Delta \mathrm{C} t}$. Probe and primer sequences were as follows: $11 \beta$ HSD1, forward primer AGGAAAGCTCATGGGAGGACTAG, reverse ATGGTGAATATCATCATGAAAAAGATTC, probe CATGCTCATTCTCAACCACATCACCAACA; GR $\alpha$, forward AACTGGCAGCGGTTTTATCAACT, reverse AATACTCATGGTCTTATCCAAAAATGTTT, probeATTCTATGCATGAAGTGGTGGAAAATCTCCTTAACTATTG; GR $\beta$ forward AACTGGCAGCGGTTTTATCAACT, reverse TGTGTGAGATGTGCTTTCTGGTT, probe AACTCTTGGATTCTATGCATGAAAATGTTATGTGGTTA. TaqMan assays for osteoprotegerin (Hs00171068_m1) and cyclooxygenase-2 (Hs00153133_m1) were from Applied Biosystems.

\section{Western blot analysis}

The expression of $11 \beta$-HSD1 protein was determined by western blotting using a specific $11 \beta-H S D 1$ antibody (Binding Site, UK). ${ }^{11}$ Expression was analysed relative to $\beta$-actin. Densitometry was performed on three separate experiments using primary synovial fibroblasts from three different individuals.

\section{$11 \beta$-HSD enzyme activity assays}

Confluent cells were cultured in medium containing $100 \mathrm{nM}$ cortisone (to measure oxo-reductase/activation activity) or cortisol (dehydrogenase/inactivation activity) along with tritiated tracer. Steroids were extracted using dichloromethane and separated by thin-layer chromatography using ethanol:chloroform (8:92) as the mobile phase. Thin-layer chromatography plates were analysed by Bioscan imager (Bioscan, Washington, DC,
USA) and the fractional conversion of steroids was calculated. The protein concentration was assessed by a 96-well assay kit (Bio-Rad, Hercules, California, USA). Results were expressed as $\mathrm{pmol}$ product/h per milligram of protein and experiments were performed in triplicate.

\section{Functional consequences of induction of $11 \beta-$ HSD1 activity on IL-6 production}

Primary fibroblasts were incubated with no treatment, $10 \mathrm{ng} / \mathrm{ml}$ IL-1 $\beta, 100 \mathrm{nmol} /$ litre dexamethasone or both for $24 \mathrm{~h}$. Medium was then changed to fresh medium without cytokines or glucocorticoids and left for $24 \mathrm{~h}$. Cells were then treated for $24 \mathrm{~h}$ with or without $100 \mathrm{nmol} /$ litre cortisone and media collected. Soluble IL- 6 was measured by sandwich ELISA (BD Biosciences, Torreyana, San Diego, California, USA). Data were expressed as the production of IL- 6 in $\mathrm{pg} / \mathrm{well}$.

\section{Statistics}

Data were reported as mean \pm standard error (SE) of replicate mean values. One-way and two-way analysis of variance analyses with Tukey post-hoc test were performed using SPSS Data Editor and SigmaStat software.

\section{RESULTS}

\section{Inflammatory cytokines and glucocorticoids synergistically} induce $11 \beta$-HSD1 expression and activity in synovial fibroblasts As previously reported, when used in isolation, pro-inflammatory cytokines (IL-1 $\beta / T N F \alpha$ ) and glucocorticoids increased $11 \beta$ HSD1 mRNA expression and oxidoreductase enzyme activity in primary human synovial fibroblasts (figure 1A,B). However, the combination of IL-1 $\beta$ and glucocorticoids substantially increased 11 $\beta$-HSD1 mRNA levels and enzyme activity relative to either individual treatment. This pattern of activity was consistently seen in cells from three separate donors and data reflect the combined results from these three patients. In keeping with our previous report, no dehydrogenase activity was detectable in these cells. ${ }^{4}$ Western blotting using extracts from primary synovial fibroblasts showed that this change was caused by increased $11 \beta-H S D 1$ protein expression (figure 1C).

\section{Inflammatory cytokines and glucocorticoids synergistically induce 11 $\beta$-HSD1 in osteoblasts}

The same pattern of induction of $11 \beta-H S D 1$ mRNA and enzyme activity was also observed in primary human osteoblasts and MG63 cells (figure 2A,B). Similar results were obtained using $\mathrm{TNF} \alpha$ as co-treatment (for MG-63 cells increases in mRNA expression relative to untreated cells: 54-fold with $10 \mathrm{ng} / \mathrm{ml}$ TNFo; 19-fold with 100 nM dexamethasone; 2952-fold with combined $\mathrm{TNF} \alpha /$ dexamethasone), or when using cortisol as co-treatment (increases in mRNA expression: 12-fold with 100 nM cortisol; 1150-fold with combined TNF $\alpha$ /cortisol).

\section{Synergistic response to inflammatory cytokines and glucocorticoids is specific for 11 $\beta$-HSD1}

Analyses using primary synovial fibroblasts confirmed that a synergistic effect of co-treatment with IL-1 $\beta$ and dexamethasone was not observed for other glucocorticoid signalling components such as GR $\alpha / \beta$ (figure $2 \mathrm{C}$ ). Moreover, analysis of two cytokine gene targets, osteoprotegerin and cyclooxygenase-2, showed that although the expression of both was increased following IL-1 $\beta$ treatment, this effect was abrogated rather than potentiated in combination with dexamethasone (figure $2 \mathrm{C}$ ). 
A

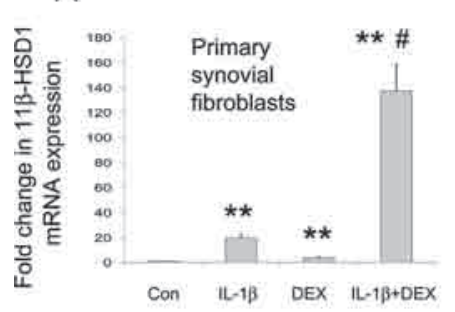

B
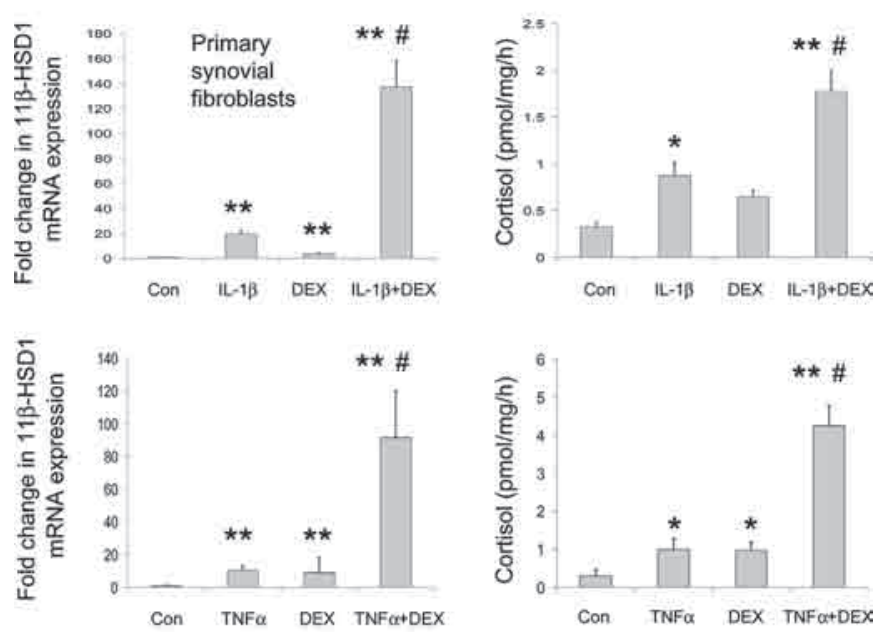

C

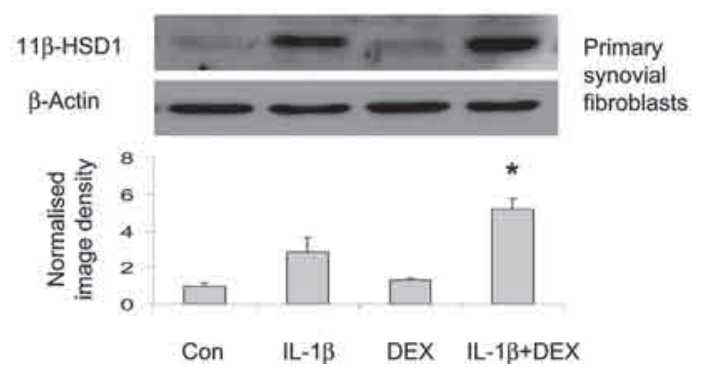

Figure 1 Synergistic induction of $11 \beta$-hydroxysteroid dehydrogenase type 1 (11 $\beta$-HSD1) mRNA, activity and protein expression in synovial fibroblasts by inflammatory cytokines and glucocorticoids. (A) Effect of $10 \mathrm{ng} / \mathrm{ml} \mathrm{IL-1} \beta /$ tumour necrosis factor alpha (TNF $\alpha), 100 \mathrm{nM}$ dexamethasone (DEX) or combined IL-1 $\beta / T N F \alpha$ and dexamethasone on the expression of $11 \beta$-HSD1 mRNA expression as determined by real-time reverse transcriptase PCR. ${ }^{*} p<0.05,{ }^{* *} p<0.01$ compared with control (Con); \#p<0.05 compared with single treatments. Data are based on cultures from three individuals. (B) Effect of $10 \mathrm{ng} / \mathrm{ml}$ IL-1 $\beta / T N F \alpha, 100 \mathrm{nM}$ dexamethasone or combined IL-1 $\beta / T N F \alpha$ and dexamethasone on $11 \beta$-HSD1 catalysed synthesis of $3 \mathrm{H}$-cortisol from $3 \mathrm{H}$-cortisone (oxo-reductase activity) as determined by scanning thinlayer chromatography. Data are shown as pmoles/h per milligram of protein and are based on cultures from three individuals. (C) Effect of IL-1 $\beta$, dexamethasone or combined IL-1 $\beta /$ dexamethasone on $11 \beta$ HSD1 protein expression in primary cultures of synovial fibroblasts as determined by western blotting. Expression is relative to $\beta$-actin. Densitometry data reflect expression in three separate primary cultures of synovial fibroblasts derived from different patients.

\section{Synergistic induction of 11 $\beta$-HSD1 expression occurs in a limited number of cell types}

The effects of IL- $1 \beta$ and dexamethasone were examined in other cell types. A synergistic effect on 11/-HSD1 expression was seen in primary skin fibroblasts isolated from the patients from whom synovial fibroblasts were generated (figure $3 \mathrm{~A}$ ). This effect was not, however, observed in Hs68 primary fibroblasts derived from foreskin. Adipocytes and preadipocytes express $11 \beta$-HSD1, and expression is increased by pro-inflammatory cytokines or glucocorticoids. ${ }^{12}{ }^{13}$ The effect of treatments in isolation or combination was examined in Chub-S7 human differentiating adipocytes (figure $3 \mathrm{~A}$ ). Glucocorticoid treatment alone induced $11 \beta$-HSD1 expression in undifferentiated cells with no effect of IL-1 $\beta$ or any additional effect of IL- $1 \beta$ in combination with dexamethasone evident. In differentiated adipocytes,
A
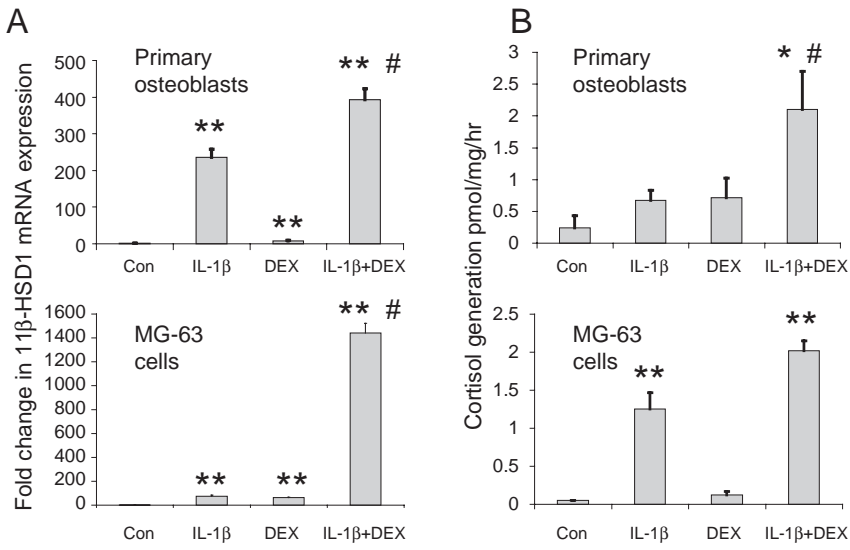

C
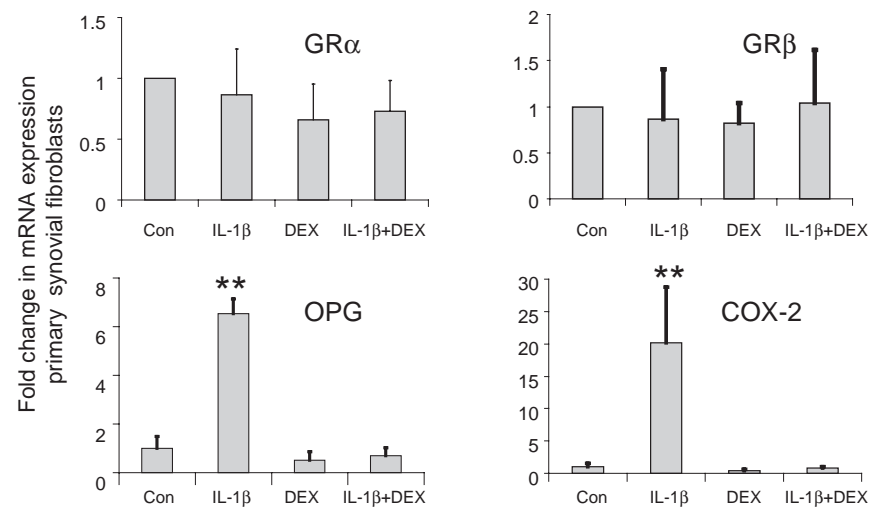

Figure 2 Synergistic induction of $11 \beta$-hydroxysteroid dehydrogenase type 1 (11ß-HSD1) mRNA and activity in human osteoblastic cell culture models by inflammatory cytokines and glucocorticoids. (A) Effect of $10 \mathrm{ng} / \mathrm{ml}$ IL-1 $\beta, 100 \mathrm{nM}$ dexamethasone (DEX) or combined IL-1 $\beta$ / dexamethasone on the expression of 11 $\beta$-HSD1 mRNA in primary human osteoblasts and MG-63 cells as determined by real time reverse transcriptase PCR. Data are normalised for $18 \mathrm{~S}$ rRNA expression and are shown as fold-change relative to an arbitrary value of one for vehicleonly control cells (Con). ${ }^{*} p<0.05,{ }^{* *} p<0.01$ compared with control; $\# p<0.05$ compared with single treatments, $N=3$. (B) Effect of $10 \mathrm{ng} /$ $\mathrm{ml}$ IL-1 $\beta, 100 \mathrm{nM}$ dexamethasone and combined IL-1 $\beta /$ dexamethasone on $11 \beta$-HSD1 catalysed synthesis of $3 \mathrm{H}$-cortisol from $3 \mathrm{H}$-cortisone (oxoreductase activity) by primary human osteoblasts and MG-63 cells as determined by scanning thin-layer chromatography. Data are shown as pmoles $/ \mathrm{h}$ per milligram of protein, $\mathrm{N}=3$. (C) Effects of combined IL-1 $\beta$ and dexamethasone on expression of mRNA for $\mathrm{GR} \alpha$, $\mathrm{GR} \beta$, osteoprotegerin (OPG) and cyclooxygenase-2 (COX-2) in primary synovial fibroblasts demonstrating that synergism is specific for the induction of $11 \beta-H S D 1$ expression. Data are based on cultures from three individuals.

IL-1 $\beta$ and dexamethasone in isolation had a small impact on $11 \beta$-HSD1 mRNA expression, but the effect of the combination was less than either treatment alone. This indicates that synergistic interactions are not universal in cells expressing $11 \beta-H S D 1$ activity or of stromal origin.

\section{Synergistic induction of $11 \beta-H S D 1$ varies with osteoblast differentiation}

To investigate whether the synergistic induction of $11 \beta-\mathrm{HSD}$ in osteoblasts occurs at specific stages of osteoblast differentiation, we assessed the effects of IL-1 $\beta$ and dexamethasone on $11 \beta$-HSD1 expression in SV-HFO human fetal osteoblasts. In previous studies we showed that cells readily express $11 \beta$ HSD1 mRNA and enzyme activity when cultured without 
glucocorticoids, and that this activity aids the mineralisation of mature cultures. However, when treated with $100 \mathrm{nM}$ dexamethasone, cells lose the expression of $11 \beta$-HSD1, suggesting that this pathway becomes redundant in the presence of exogenous dexamethasone. ${ }^{1415}$ Data in figure $3 \mathrm{~B}$ confirmed previously reported observations, that cells show an increase in 11 $\beta$-HSD1 expression between days 7 and 14 of culture, with a subsequent decline at day 21 . In cells with low $11 \beta-H S D 1$ expression (days 7 and 21 cultures) treatment with either IL-1 $\beta(10 \mathrm{ng} / \mathrm{ml})$ or dexamethasone $(100 \mathrm{nM})$ for the last $24 \mathrm{~h}$ of culture induced the expression of $11 \beta$-HSD1. As with other osteoblast models, this response was enhanced when IL-1 $\beta$ and dexamethasone were added together. Cells at day 14 did not show altered $11 \beta$-HSD1 expression with single or combined treatments, but basal expression was already as high as the maximal expression seen at other times with combined treatments. SV-HFO cells exposed to continual dexamethasone treatment showed suppressed 11ß-HSD1 expression at all time points but high
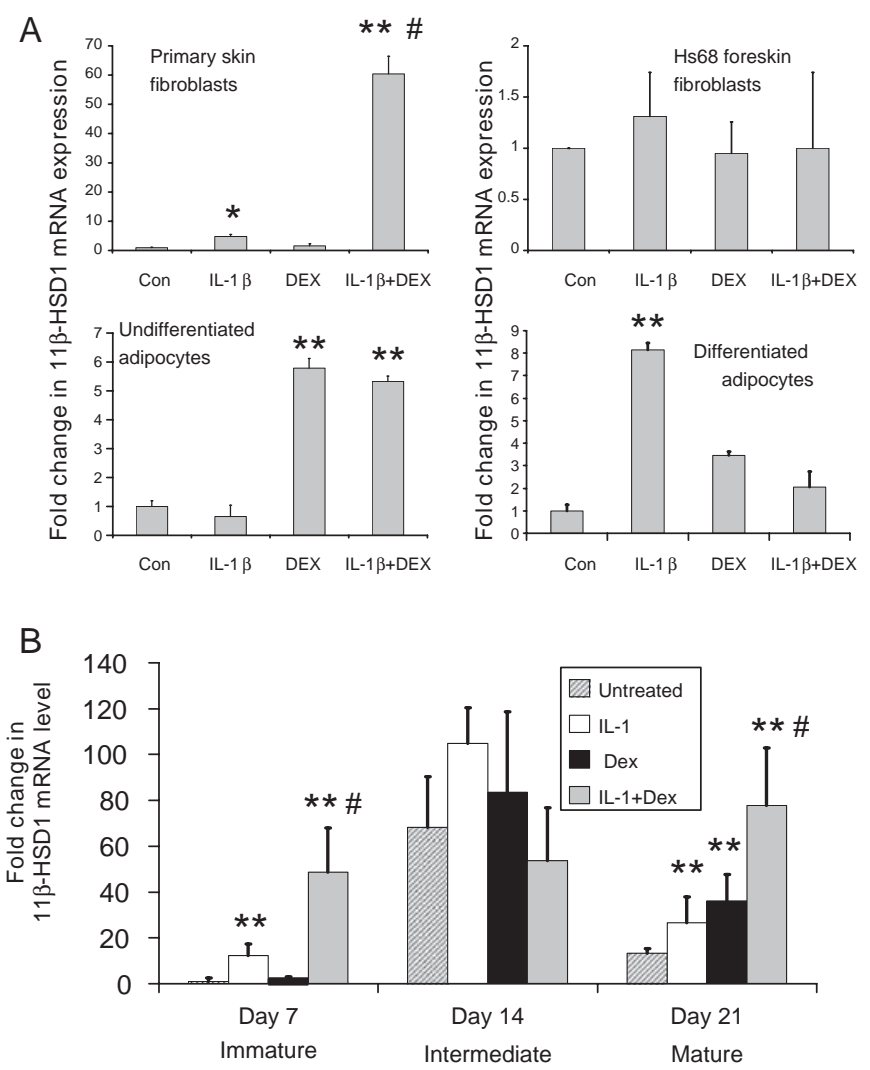

Figure 3 Synergistic effect of IL-1 $\beta$ and dexamethasone (DEX) is restricted to fibroblasts and osteoblasts and depends on the stage of osteoblast differentiation. (A) Effects of combined IL-1 $\beta$ and dexamethasone on the expression of mRNA for $11 \beta$-hydroxysteroid dehydrogenase type 1 (11 $\beta$-HSD1) in primary skin fibroblasts, foreskin fibroblasts, undifferentiated and differentiated adipocytes. ${ }^{*} \mathrm{p}<0.05$ and ${ }^{* *} \mathrm{p}<0.01$ compared with control (Con); \#p $<0.05$ compared with single treatments, $N=3$. (B) Synergistic induction of $11 \beta$-HSD1 occurs at different stages of osteoblast differentiation. Human osteoblastic SV-HFO cells were cultured for 7, 14 or 21 days under the following

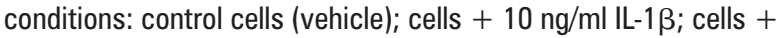
dexamethasone for $24 \mathrm{~h}$; cells $+\mathrm{IL}-1 \beta+$ dexamethasone for $24 \mathrm{~h}$. At each time point RNA was isolated for real-time reverse transcriptase PCR analysis. Data are shown as the mean \pm SE fold-induction in $11 \beta$ HSD1 mRNA expression relative to day 7 cells. ${ }^{* *} p<0.01$ compared with untreated control at each time point; $\# p<0.05$ compared with single treatments, $\mathrm{N}=6$. expression when cells were co-treated with IL-1 $\beta$ for $24 \mathrm{~h}$ (data not shown).

\section{Dose response and time course of $11 \beta-H S D 1$ induction}

Dose-dependency studies of MG-63 cells indicated that synergistic interaction between IL-1 $\beta$ and dexamethasone occurred at all tested concentrations of IL-1 $\beta$ (figure 4A). Synergistic induction of $11 \beta-H S D 1$ was also seen across a range of concentrations of dexamethasone (1-100 nM; data not shown). The effect of combined IL-1 $\beta$ with dexamethasone compared with IL-1 $\beta$ alone was seen at $8 \mathrm{~h}$, and the difference was most dramatic at 24-48 h (figure 4B, expression of dexamethasone alone not shown because the relative expression was very low).

\section{Functional impact of synergistic induction of $11 \beta-H S D 1$ activity in primary fibroblasts}

The functional impact of the synergistic induction of $11 \beta-H S D 1$ activity was examined in synovial fibroblasts treated with IL-1 $\beta$, dexamethasone or a combination of IL-1 $\beta$ and dexamethasone for $24 \mathrm{~h}$ followed by $24 \mathrm{~h}$ without treatment (washout period). Cells were then cultured for $24 \mathrm{~h}$ with or without $100 \mathrm{nM}$ cortisone before media were removed for the analysis of IL- 6 levels. Under these conditions the addition of IL-1 $\beta$ or dexamethasone in isolation did not significantly sensitise cells to cortisone (figure 5). However, cells treated with the combination of IL-1 $\beta$ and dexamethasone were markedly responsive to cortisone, as evidenced by a significant reduction in IL- 6 production.

A

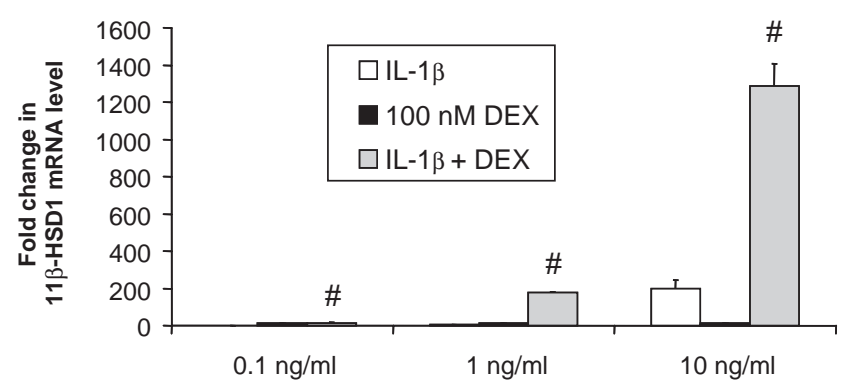

B

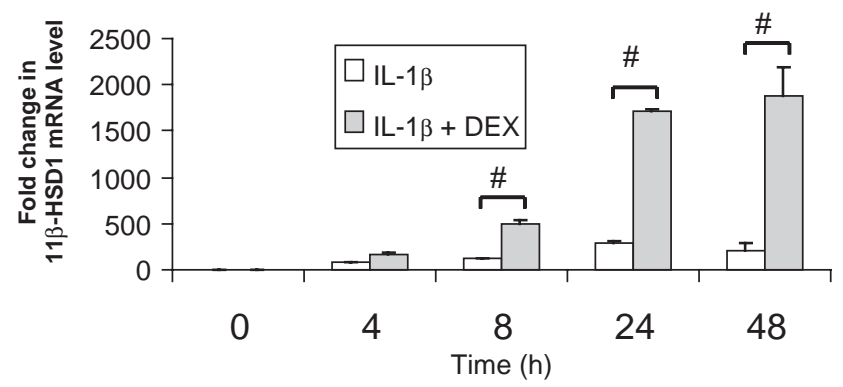

Figure 4 Dose response and time course of $11 \beta$-hydroxysteroid dehydrogenase type 1 (11 $\beta$-HSD1) induction. (A) Dose-response effects of $10 \mathrm{ng} / \mathrm{ml} \mathrm{IL-1} \beta, 100 \mathrm{nM}$ dexamethasone (DEX) and combined IL-1 $\beta$ and dexamethasone on 11 $\beta$-HSD1 mRNA expression in MG-63 cells. Combined treatment at $0.1 \mathrm{ng} / \mathrm{ml}$ and all treatments at 1 and $10 \mathrm{ng} /$ $\mathrm{ml}$ significantly induced expression compared with untreated controls $(p<0.05) . \# p<0.05$ compared with effects of single treatments at each cytokine concentration, $N=3$. (B) Time course of induction of $11 \beta$-HSD1 mRNA following treatment of MG-63 cells with IL-1 $\beta$ or IL-1 $\beta+$ dexamethasone. All treatments significantly induced expression compared with time $0(p<0.01)$. \#p<0.05 compared with effects of single treatments at each time point, $\mathrm{N}=3$. 


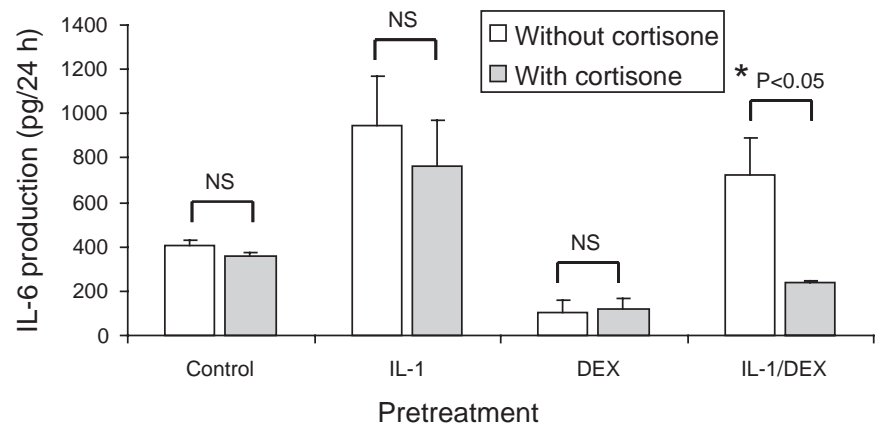

Figure 5 Functional impact of $11 \beta$-hydroxysteroid dehydrogenase type $1(11 \beta$-HSD1) synergism in primary synovial fibroblasts. The functional response to the synergistic induction of $11 \beta$-HSD1 activity by IL-1 $\beta$ and dexamethasone (DEX) was assessed in primary synovial fibroblasts. Cells were treated for $24 \mathrm{~h}$ with either IL-1 $\beta$, dexamethasone or combined IL-1 $\beta$ and dexamethasone. Medium was then removed and cells were treated for a washout period of $24 \mathrm{~h}$ with unsupplemented medium. The functional impact of differences in $11 \beta$-HSD1 expression was then examined by treating cells for $24 \mathrm{~h}$ with cortisone (inactive substrate for $11 \beta$-HSD1). Data are shown as pg IL-6 produced during this $24 \mathrm{~h}$ incubation period. Data are based on cultures from three individuals.

\section{DISCUSSION}

We found that the exposure of synovial fibroblasts or osteoblasts to both proinflammatory cytokines and glucocorticoids dramatically increased glucocorticoid-generating capacity relative to each factor in isolation. This synergistic induction of glucocorticoid-generating capacity had important functional consequences. This potentiation, rather than suppression, of localised inflammation-induced expression of $11 \beta$-HSD1 by glucocorticoids may be an endogenous mechanism to reduce synovitis. However, with persistent inflammation, the resulting tissue-specific elevation of glucocorticoid generation is likely to contribute to periarticular bone loss in inflammatory joint disease, and could explain why inflammatory diseases sensitise bone to the effects of therapeutic glucocorticoids.

There are multiple interactions between pro-inflammatory cytokines and glucocorticoids. In most situations glucocorticoids antagonise the actions and production of pro-inflammatory cytokines through the inhibition of activator protein 1 or nuclear factor kappa B signalling pathways. ${ }^{10}$ Additive or synergistic interaction is less commonly reported. ${ }^{16-18}$ Synergistic interactions in these situations have been reported to be by effects on p38-mitogen-activated protein kinase, mitogen-activated protein kinase phosphatase or increased mRNA stability. A glucocorticoid-cytokine interaction has previously been reported for $11 \beta$-HSD1 in chorionic trophoblast cells. ${ }^{19}$ On the basis of promoter-reporter assays it was concluded that this effect was transcriptionally mediated by means of the proximal promoter.

Recent reports have demonstrated $11 \beta-H S D 1$ expression in synovial fibroblasts in vitro and in vivo. ${ }^{4} 620$ Local generation of active glucocorticoids in patients with inflammatory arthritis was demonstrated on the basis of synovial fluid corticosteroid measurements, and this activity correlated with measures of inflammation. ${ }^{6}$ This increase in local steroid generation might be aimed at resolving prolonged synovial inflammation. It is possible that in transient synovitis, locally produced glucocorticoids reduce inflammation and hasten resolution. However, in rheumatoid arthritis, this increased generation of glucocorticoids does not lead to the complete resolution of inflammation. The reason for this failure is unclear, but the presence of cells within the joint that are resistant to locally produced glucocorticoids is a potential explanation. ${ }^{62021}$

The mechanisms underlying periarticular bone loss in inflammatory arthritis remain unclear. Increased bone resorption due to increased osteoclast formation has been proposed, and the pharmacological inhibition of bone resorption can prevent bone loss in animal models. ${ }^{22}$ However, this bone loss is not accompanied by an expected compensatory increase in bone formation. We have hypothesised that this uncoupling of formation from resorption is due to the production of glucocorticoids within periarticular osteoblasts or nearby synovium. ${ }^{5}$ The findings in this study support this hypothesis and also suggest that glucocorticoids generated within the synovium could increase glucocorticoid-generating capacity in periarticular bone in the presence of proinflammatory cytokines. It is also possible that glucocorticoids generated within osteoblasts could have effects on synovial fibroblasts or immune cells within the synovium.

How glucocorticoids potentiate the effects of proinflammatory cytokines on $11 \beta-H S D 1$ transcription remains unclear. The finding that adipocytes are responsive to glucocorticoid or cytokine induction of $11 \beta$-HSD1 expression but not the combination indicates that tissue-specific factors are important. The reason for the variation of induction across osteoblast differentiation also needs to be determined. It is possible that the lack of effect during mid-differentiation is explained by the high expression of $11 \beta$-HSD1 at this stage. We have previously shown that induction across differentiation is mediated by the proximal promoter. ${ }^{14}$ It will be important to characterise the tissue specificity of these effects given that many cell types express $11 \beta$-HSD1. ${ }^{11} 23-25$ Our results show clear heterogeneity of this effect across tissues.

The identification of a powerful interaction between proinflammatory cytokines and glucocorticoids for the induction of glucocorticoid-generating capacity has implications for bone diseases. It may explain why patients with inflammatory disorders develop more bone loss with glucocorticoids than those without. ${ }^{26}$ The biological significance of the synergistic induction of $11 \beta-H S D 1$ is also unclear, but the dynamics of induction suggest that local glucocorticoid production will occur hours to days after exposure to inflammation. This may therefore be a mechanism to downregulate excessive inflammation (akin to the rise in cortisol levels due to hypothalamo-pituitary-adrenal axis activation with stress). ${ }^{27}$ The observation that only low glucocorticoid concentrations are required to induce $11 \beta-H S D 1$ synergistically may explain why even low-dose glucocorticoids are linked to bone loss in inflammatory diseases. ${ }^{28}$ These observations also need to be considered when evaluating the clinical effects of $11 \beta$-HSD1 enzyme inhibitors. ${ }^{29}$ On the basis of this study some effects of these drugs may only become apparent in the presence of both inflammation and the levels of glucocorticoids seen during stress.

Acknowledgements The authors would like to thank Laura Gathercole for help with western blot techniques.

Funding This study was funded by the Medical Research Council, UK and the Arthritis Research Campaign Project grants 17730 and 18081.

Competing interests None.

Patient consent Obtained.

Ethics approval This study was conducted with the approval of the South Birmingham Research Ethics Committee.

Provenance and peer review Not commissioned; externally peer reviewed. 


\section{REFERENCES}

1. Walsh NC, Crotti TN, Goldring SR, et al. Rheumatic diseases: the effects of inflammation on bone. Immunol Rev 2005;208:228-51.

2. Schett G. Review: Immune cells and mediators of inflammatory arthritis. Autoimmunity 2008;41:224-9.

3. Roldán JF, Del Rincón I, Escalante A. Loss of cortical bone from the metacarpal diaphysis in patients with rheumatoid arthritis: independent effects of systemic inflammation and glucocorticoids. J Rheumatol 2006;33:508-16.

4. Hardy RS, Filer A, Cooper MS, et al. Differential expression, function and response to inflammatory stimuli of 11 beta-hydroxysteroid dehydrogenase type 1 in human fibroblasts: a mechanism for tissue-specific regulation of inflammation. Arthritis Res Ther 2006; 8 :R108.

5. Cooper MS, Bujalska I, Rabbitt E, et al. Modulation of 11 beta-hydroxysteroid dehydrogenase isozymes by proinflammatory cytokines in osteoblasts: an autocrine switch from glucocorticoid inactivation to activation. J Bone Miner Res 2001;16:1037-44.

6. Hardy R, Rabbitt EH, Filer A, et al. Local and systemic glucocorticoid metabolism in inflammatory arthritis. Ann Rheum Dis 2008;67:1204-10.

7. Cooper MS, Walker EA, Bland R, et al. Expression and functional consequences of 11 beta-hydroxysteroid dehydrogenase activity in human bone. Bone 2000;27:375-81.

8. Cooper MS, Rabbitt EH, Goddard PE, et al. Osteoblastic 11 beta-hydroxysteroid dehydrogenase type 1 activity increases with age and glucocorticoid exposure. J Bone Miner Res 2002;17:979-86.

9. Cooper MS, Blumsohn A, Goddard PE, et al. 11Beta-hydroxysteroid dehydrogenase type 1 activity predicts the effects of glucocorticoids on bone. J Clin Endocrinol Metab 2003;88:3874-7.

10. Rhen T, Cidlowski JA. Antiinflammatory action of glucocorticoids-new mechanisms for old drugs. N Engl J Med 2005;353:1711-23

11. Ricketts ML, Verhaeg JM, Bujalska I, et al. Immunohistochemical localization of type 111 beta-hydroxysteroid dehydrogenase in human tissues. J Clin Endocrinol Metab 1998;83:1325-35.

12. Bujalska IJ, Kumar S, Stewart PM. Does central obesity reflect "Cushing's disease of the omentum"? Lancet 1997;349:1210-13.

13. Tomlinson JW, Moore J, Cooper MS, et al. Regulation of expression of 11 betahydroxysteroid dehydrogenase type 1 in adipose tissue: tissue-specific induction by cytokines. Endocrinology 2001;142:1982-9.

14. Eijken M, Hewison M, Cooper MS, et al. 11Beta-hydroxysteroid dehydrogenase expression and glucocorticoid synthesis are directed by a molecular switch during osteoblast differentiation. Mol Endocrinol 2005;19:621-31.

15. Eijken M, Koedam M, van Driel M, et al. The essential role of glucocorticoids for proper human osteoblast differentiation and matrix mineralization. Mol Cell Endocrinol 2006;248:87-93.
16. Hermoso MA, Matsuguchi T, Smoak K, et al. Glucocorticoids and tumor necrosis factor alpha cooperatively regulate toll-like receptor 2 gene expression. Mol Cell Biol 2004;24:4743-56.

17. Trujillo ME, Lee MJ, Sullivan S, et al. Tumor necrosis factor alpha and glucocorticoid synergistically increase leptin production in human adipose tissue: role for p38 mitogen-activated protein kinase. J Clin Endocrinol Metab 2006;91:1484-90

18. Homma T, Kato A, Hashimoto N, et al. Corticosteroid and cytokines synergistically enhance toll-like receptor 2 expression in respiratory epithelial cells. Am J Respir Cell Mol Biol 2004;31:463-9.

19. Li W, Gao L, Wang Y, et al. Enhancement of cortisol-induced 11 beta-hydroxysteroid dehydrogenase type 1 expression by interleukin 1 beta in cultured human chorionic trophoblast cells. Endocrinology 2006;147:2490-5.

20. Schmidt $\mathbf{M}$, Weidler $\mathrm{C}$, Naumann $\mathrm{H}$, et al. Reduced capacity for the reactivation of glucocorticoids in rheumatoid arthritis synovial cells: possible role of the sympathetic nervous system? Arthritis Rheum 2005;52:1711-20.

21. Haas CS, Creighton CJ, Pi X, et al. Identification of genes modulated in rheumatoid arthritis using complementary DNA microarray analysis of lymphoblastoid $B$ cell lines from disease-discordant monozygotic twins. Arthritis Rheum 2006;54:2047-60.

22. Kong YY, Feige U, Sarosi I, et al. Activated T cells regulate bone loss and joint destruction in adjuvant arthritis through osteoprotegerin ligand. Nature 1999;402:304-9.

23. Escher G, Galli I, Vishwanath BS, et al. Tumor necrosis factor alpha and interleukin 1 beta enhance the cortisone/cortisol shuttle. J Exp Med 1997;186:189-98.

24. Zhang TY, Ding X, Daynes RA. The expression of 11 beta-hydroxysteroid dehydrogenase type I by lymphocytes provides a novel means for intracrine regulation of glucocorticoid activities. J Immunol 2005;174:879-89.

25. Rauz S, Walker EA, Shackleton $\mathrm{CH}$, et al. Expression and putative role of 11 betahydroxysteroid dehydrogenase isozymes within the human eye. Invest Ophthalmol Vis Sci 2001;42:2037-42.

26. Cooper MS, Stewart PM. Glucocorticoids and bone mineral content in the childhood nephrotic syndrome. N Engl J Med 2004;351:2655-7; author reply 2655-7.

27. Cooper MS, Stewart PM. Corticosteroid insufficiency in acutely ill patients. N Engl J Med 2003;348:727-34.

28. van Everdingen AA, Siewertsz van Reesema DR, Jacobs JW, et al. Low-dose glucocorticoids in early rheumatoid arthritis: discordant effects on bone mineral density and fractures? Clin Exp Rheumatol 2003;21:155-60.

29. Hughes KA, Webster SP, Walker BR. 11-Beta-hydroxysteroid dehydrogenase type 1 (11beta-HSD1) inhibitors in type 2 diabetes mellitus and obesity. Expert Opin Investig Drugs 2008;17:481-96 